\title{
Anatomical variations of lingual foramen and it's bony canals with cone beam computerised tomography in south indian population - a cross sectional study
}

\author{
Arun Kumar G* \\ Department of Oral Medicine and Radiology, Dr. Syamala Reddy Dental College Hospital and Research Center, No111/1, S.G.R College Main Road, Marathalli \\ Post, Banglore-560037, Karnataka, India
}

\begin{abstract}
Aim: The anatomical variations of lingual foramen \& its bony canals in three have been observed, analysed on many countries, but no study has been performed in South Indian population yet. The aim of our study was to assess the anatomical variations of lingual foramen and it's bony canals with cone-beam computed tomography (CBCT) imaging in South Indian population.

Methods: A cross-sectional study included 100 CBCT images of patients. The assessment of presence of the lingual foramen and its bony canals, the locations, sizes, length and angulations were done. The distances between the terminal end of lingual canal at the buccal and lingual side from the inferior border of the mandible and alveolar crest were measured. The effect of patient's gender on the dimensional measurements of the anatomical landmark were also assessed, $t$ test, analysis of variance (ANOVA), and pearson's correlation were used for statistical analysis and $\mathrm{P}$ value less than 0.05 was considered significant.

Results: All the 100 CBCT images showed the presence of lingual foramen. Among 100 patients, 52\% of them had two foramens in their images. The mean diameters of the upper and lower lingual foramen were 1.12 and $0.9 \mathrm{~mm}$, respectively.

Conclusion: This study proves that 3D images of CBCT can detect precise anatomic routes to prevent the complications of procedures carried out in lingual foramen region.
\end{abstract}

\section{Introduction}

The success of mandibular bone surgeries, such as implant placements, orthognathic surgeries depends on the various imaging modalities to determine the parameters of implant placement by revealing the structure of the mandible, alveolar bone shape, and volume. Most commonly Panoramic and tomographic radiographs were used to carry out these analyses [1]. However, the conventional radiographs appear only in two dimensions, and the extent of magnification (10\% to $30 \%$ ) depends on the patient anatomy as parts of the mandible can obscure key elements in the image. Cone-beam computed tomography (CBCT) can be widely used prior to implant surgeries. Multi-planar slices of CBCT, which has fixed magnification, is clinically useful in determining implant parameters and preventing damage to vulnerable structures, such as the inferior alveolar neural tubes and maxillary antrum [2].

The mental spine is in the medial region of the lingual surface of the mandible and is surrounded by foramina connected by intraosseous canals. The sublingual and submental arteries are located in the floor of the mouth and enter the mandible through these foramina, sending branches to the mylohyoid muscle, peripheral muscles, mucous membrane, and gingiva [3].

These mucosal branches settle along the lingual aspect of the mandible and may require special care prior to surgery or implants since they are known to deposit lingual cortical bone into the mandible. The most common complications of implant surgery arising in this region are: anterior dilation of inferior alveolar neural tubes, concavity of lingual bones, lingual foramina, and lingual tubes, atypical hemorrhage caused by lingual plate perforation.

Various imaging and macroscopic studies have been conducted on the morphology of the lingual foramina of the mandible, in part because of the increased diagnostic information gained using imaging modalities such as cone beam computed tomography (CBCT).

Our study performed radiological and statistical analyses on the appearance frequency and distribution of lingual foramina in mandibular cortical bone in South Indian population, with the aim of preventing clinical complications during surgical procedures.

\section{Materials and methods}

A descriptive analytical cross-sectional study was conducted on 100 CBCT scans of mandible (50 males and 50 females) from patients, who visited a diagnostic centre were randomly selected after considering the following criteria. The inclusion criteria included: presence of

Correspondence to: Arun Kumar G, Department of Oral Medicine and Radiology, Dr. Syamala Reddy Dental College Hospital and Research Center, No111/1, S.G.R College Main Road, Marathalli Post, Banglore-560037, Karnataka, India; Tel: +91-88892830433; E-mail: arunkumarg11061987@gmail.com

Key words: anatomy, cone-beam computed tomography, lingual canal, lingual foramen

Received: May 24, 2017; Accepted: June 26, 2017; Published: June 29, 2017 
Kumar AG (2017) Anatomical variations of lingual foramen and it's bony canals with cone beam computerised tomography in south indian population - a cross sectional study

all lower erupted anterior dentition; male/female aged 18 years or older, and absence of any pathological conditions or deformities in the jaws. The exclusion criteria were: inadequate $\mathrm{CBCT}$ image quality (patient movement, operator errors etc., CBCT scans that did not include mandible, history of trauma or orthognathic surgery, presence of pathologic bone disease or unerupted teeth in related region and syndromic patients. All patients had their CBCT scans taken for other purposes and they had informed consent for participation in this study. The selected scans had paraxial slices with slice thickness of 0.3 $\mathrm{mm}$. The lingual foramina region was in the CBCT scans. The CBCT examinations were carried out for every patient with Carestream 9300 $3 \mathrm{D}$ imaging system. Full rotation scan was performed with $70-90 \mathrm{kVp}$, 5-10 mA and voxel size of 90-180 m. the size of field of view will be $10 \times 5 \mathrm{~cm}$. All images were taken using volume 1 (high-resolution) and high-contrast options. The effect of anatomical variations of greater palatine region on patient's gender were evaluated using 18 different parameters (Figure 1-12 and Table 1).

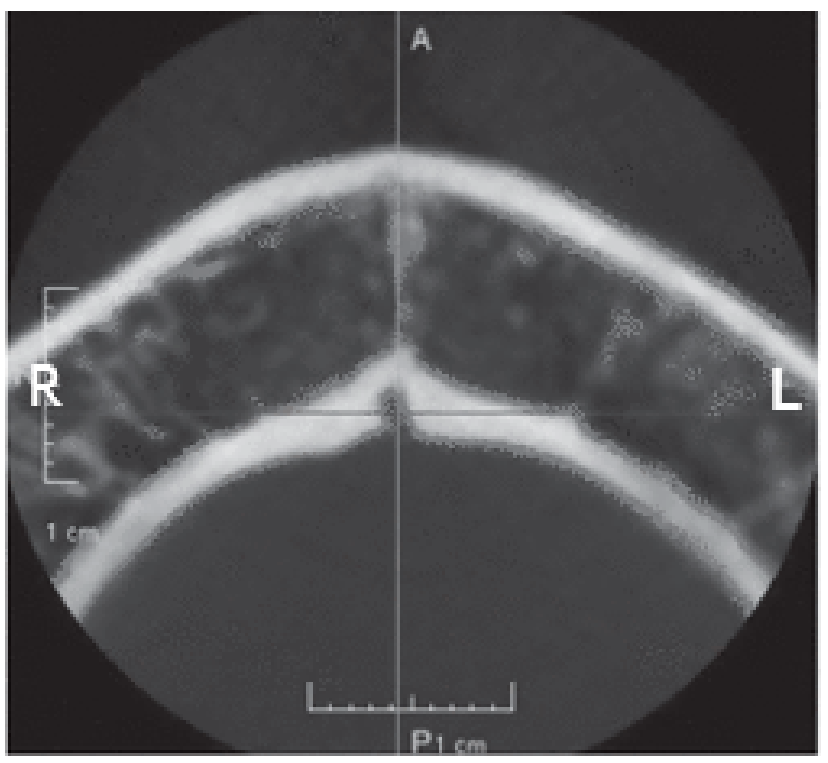

Figure 1. Anatomical location of lingual foramen
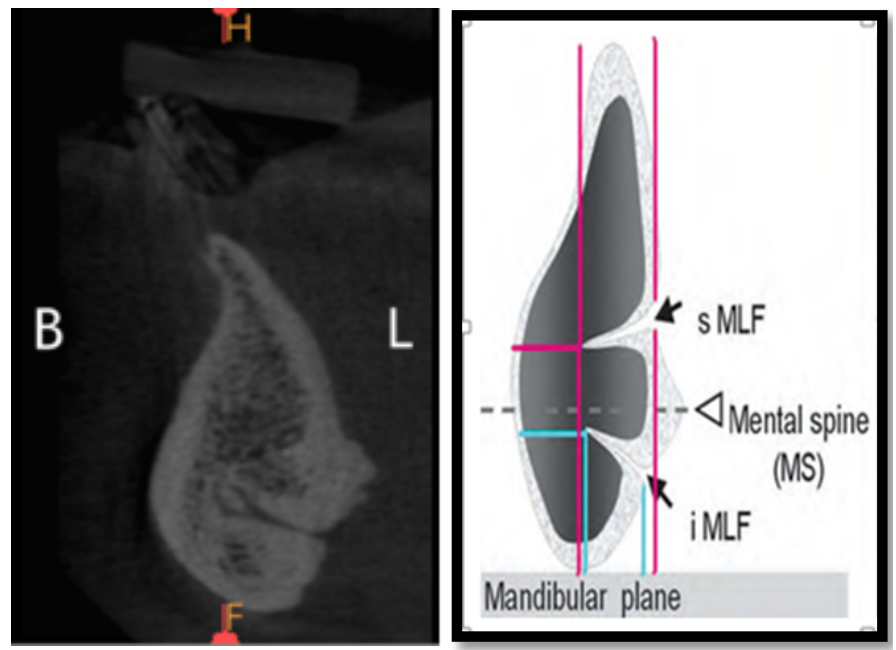

Figure 2. Anatomical location of lingual canals

Canal trajectory in axial section;

Canal trajectory in coronal section;

The frequency with which lingual foramen and their bony canals perforated the lingual cortex;

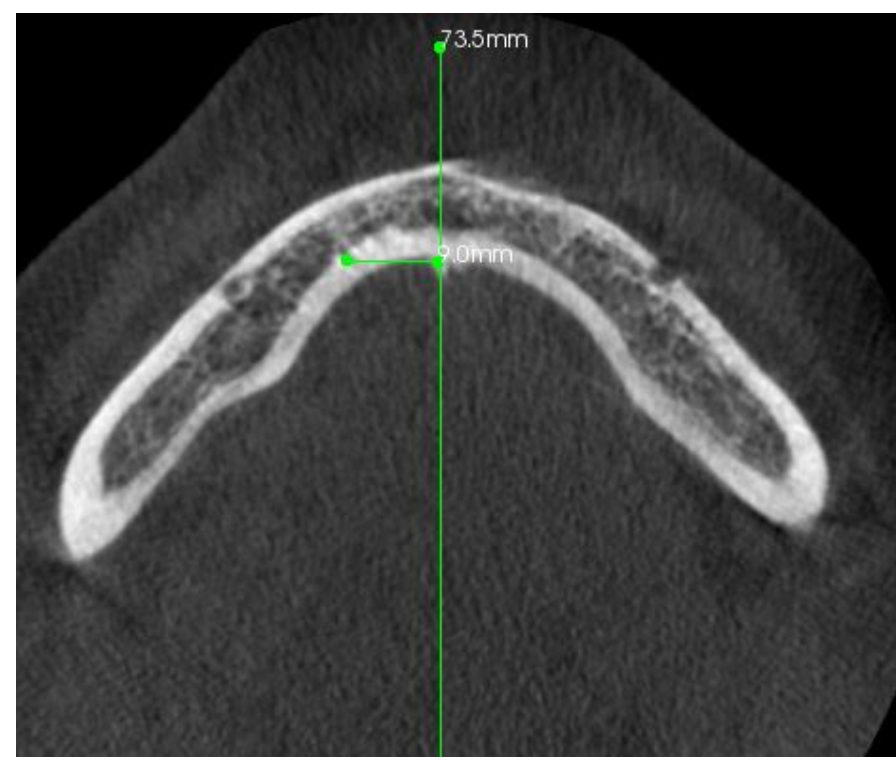

Figure 3. The distance between the lingual canal and the midline
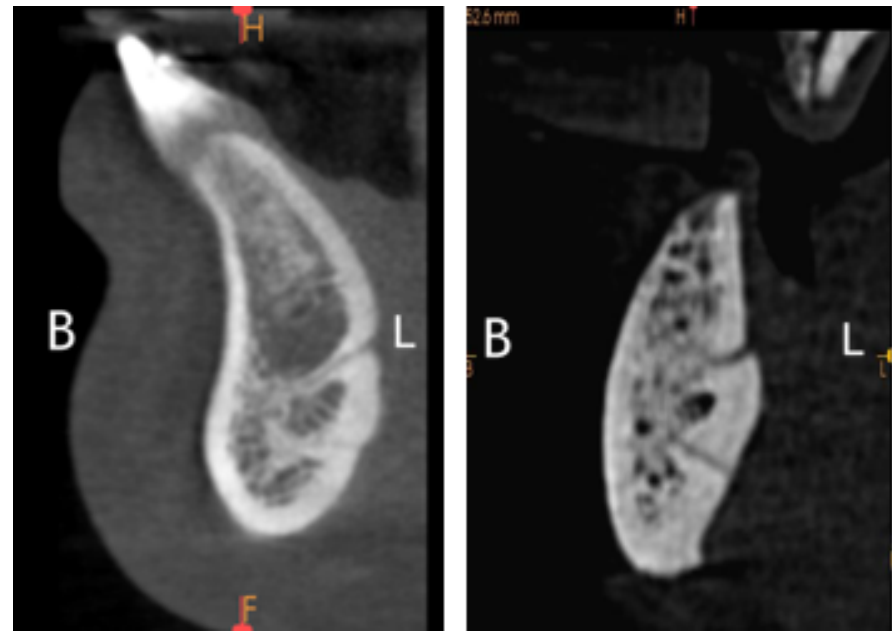

Figure 4. Number of lingual foramen and lingual canals

\section{Statistical analysis}

The analysis was done using the distance measuring tool of CS $3 \mathrm{D}$ software and the images were saved as JPEG. The measurements were repeated 2 months later and intra-examiner agreement was performed (Dahlberg's error and paired T test). All data were evaluated using SPSS software version 19 package.

A paired T test ( $\mathrm{P} 0.05)$ was conducted to compare the measurements from the right and left side, and a T test was conducted to compare the values between the sexes. Independent t-test was used to compare the LF values and the measurements made. One-way analysis of variance (ANOVA) was used to compare the length of lingual canal and other measurements made between the two study groups. A P-value less than the 0.05 level of significance was considered statistically significant. Further Discriminant analysis (ROC analysis) was used to assess the validity of linear measurements used in this study in differentiation of male gender from female according to method given by Sorlie (1995). (Table 2 and Figure 13) 
Kumar AG (2017) Anatomical variations of lingual foramen and it's bony canals with cone beam computerised tomography in south indian population - a cross sectional study

Table 1. Anatomical position of the lingual foramen

\begin{tabular}{|c|c|c|c|c|c|c|}
\hline & & & \multicolumn{4}{|c|}{ Anatomical Position - Foramen } \\
\hline & & & Right & Left & Median & Total \\
\hline \multirow{4}{*}{ Gender } & \multirow{2}{*}{ Male } & Count & 18 & 22 & 10 & 50 \\
\hline & & $\%$ within Gender & $36.0 \%$ & $44.0 \%$ & $20.0 \%$ & $100.0 \%$ \\
\hline & \multirow{2}{*}{ Female } & Count & 18 & 24 & 8 & 50 \\
\hline & & $\%$ within Gender & $36.0 \%$ & $48.0 \%$ & $16.0 \%$ & $100.0 \%$ \\
\hline \multirow{3}{*}{\multicolumn{2}{|c|}{ Total }} & Count & 36 & 46 & 18 & 100 \\
\hline & & $\%$ within Gender & $36.0 \%$ & $46.0 \%$ & $18.0 \%$ & $100.0 \%$ \\
\hline & & $\begin{array}{c}\% \text { within Anatomical } \\
\text { Position }\end{array}$ & $100.0 \%$ & $100.0 \%$ & $100.0 \%$ & $100.0 \%$ \\
\hline
\end{tabular}

Table 2. Validity parameters to predict male and female genders using roc analysis

\begin{tabular}{|c|c|c|c|c|c|}
\hline PARAMETER & GENDER & TYPICAL CUT-OFF (mm) & SENSITIVITY \% & SPECIFICITY \% & ACCURACY \% \\
\hline \multirow{2}{*}{$\begin{array}{l}\text { Lingual foramen-Alveolar } \\
\text { crest }\end{array}$} & MALES & 17.01 & 92.3 & 7.7 & 79.7 \\
\hline & FEMALES & 12.52 & 70.2 & 51.3 & 58.8 \\
\hline \multirow{2}{*}{$\begin{array}{l}\text { Lingual Foramen-Inferior } \\
\text { cortex }\end{array}$} & MALES & 10.79 & 84 & 50 & 60.8 \\
\hline & FEMALES & 8.94 & 47.4 & 78.3 & 62.8 \\
\hline \multirow{2}{*}{$\begin{array}{l}\text { Lingual Foramen-Buccal } \\
\text { plate }\end{array}$} & MALES & 9.58 & 86.2 & 60.8 & 72.3 \\
\hline & FEMALES & 8.4 & 74.8 & 84.7 & 79.7 \\
\hline \multirow{2}{*}{ Buccal end-Alveolar crest } & MALES & 16.9 & 94 & 52.5 & 67.9 \\
\hline & FEMALES & 12.1 & 76.5 & 84.0 & 80.2 \\
\hline \multirow{2}{*}{ Buccal end-Inferior cortex } & MALES & 8.24 & 74.8 & 79.7 & 88.6 \\
\hline & FEMALES & 7.5 & 78.3 & 62.8 & 68.6 \\
\hline \multirow{2}{*}{ Buccal end-Buccal plate } & MALES & 6.14 & 84.2 & 80.2 & 82.7 \\
\hline & FEMALES & 5.5 & 100 & 51.1 & 50.7 \\
\hline
\end{tabular}

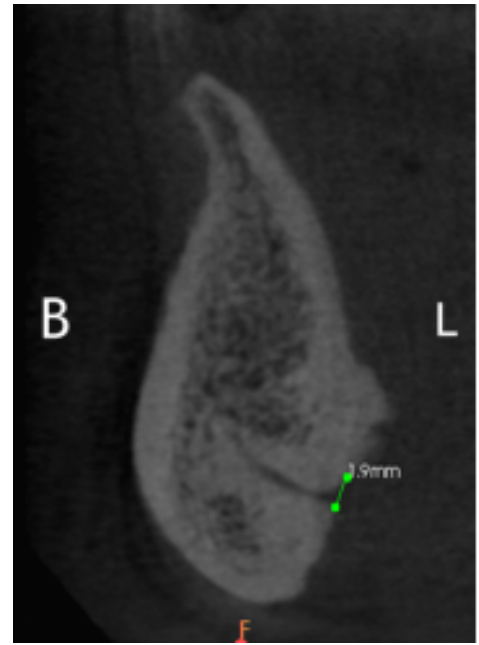

Figure 5. Diameter of lingual foramen

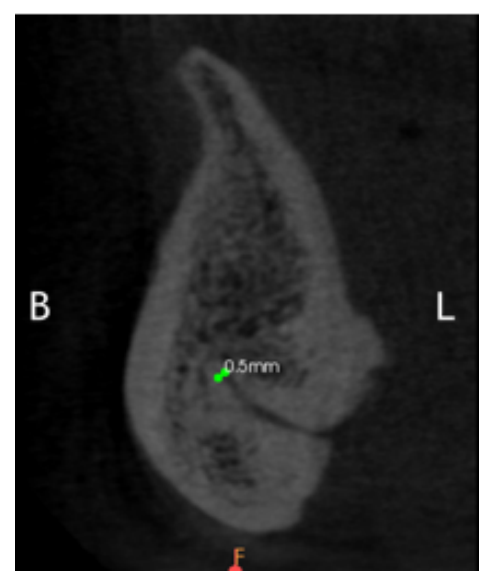

Figure 6. Diameter of buccal end of lingual canal

\section{Results}

CBCT imaging of the mandible, from 100 patients which included 50 males (50\%) and 50 females (50\%), were investigated. The mean age was 52.37 (SD: 13.33) years, range 18-70 years. From the 100 mandibles investigated, all patients had at least one lingual foramen, $58 \%$ had single lingual foramen, $42 \%$ had two lingual foramen and accessory canals were observed in $40 \%$ of the mandibles analyzed.

In relation to genial tubercles, the canals were found right above them in $39 \%$ of the cases (Figure 2), below in $45 \%$ (Figure 3) and above and below (when there were multiple canals) in $16 \%$ of the cases. The measurements regarding the position of the foramina were only performed for the most upper one, in case of multiple canals. (Table 3 )

The horizontal distances of a-MLFs from the midline are summarized in Table 4. No significant differences were observed between genders.

The lingual vascular canals traversed the bone to a variable extent, $20 \%$ penetrated only the lingual third of the width, $48 \%$ reached the middle third and $32 \%$ of the canals spreaded to the buccal third.

The orientation of the lingual vascular canals was evaluated in the sagittal plane. $54 \%$ of the canals had descending trajectory, $14 \%$ were solely anterior and $32 \%$ had an ascending trajectory. The results are consistent with similar studies [4].

In the axial plane, $49 \%$ of the lingual vascular canals had a trajectory slightly to the right, $23 \%$ were slightly to the left and $28 \%$ were oriented anteriorly. $87.9 \%$ of the canals had a single trajectory, while $12.1 \%$ presented bifurcations (Figure 5).

The average length of the lingual canals was 6.37 (SD 1.99) $\mathrm{mm}$. The mean diameter of the opening of the lingual foramen at the lingual side was 1.07 (SD 0.44$) \mathrm{mm}$. $61 \%$ of the canals had a diameter greater than $1 \mathrm{~mm}$ and if they are passed by arteries with a similar diameter, these vessels are large enough to cause bleeding in the floor of the 
Kumar AG (2017) Anatomical variations of lingual foramen and it's bony canals with cone beam computerised tomography in south indian population - a cross sectional study

Table 3. Anatomical position of lingual canal

\begin{tabular}{|c|c|c|c|c|c|c|}
\hline & & & \multicolumn{3}{|c|}{ Anatomical Position - Canal } & \multirow[b]{2}{*}{ Total } \\
\hline & & & $\begin{array}{l}\text { Above genial } \\
\text { tubercle }\end{array}$ & $\begin{array}{l}\text { Below genial } \\
\text { tubercle }\end{array}$ & Above and below the genial tubercle & \\
\hline \multirow{4}{*}{ Gender } & \multirow{2}{*}{ Male } & Count & 18 & 22 & 10 & 50 \\
\hline & & $\%$ within Gender & $36.0 \%$ & $44.0 \%$ & $20.0 \%$ & $100.0 \%$ \\
\hline & \multirow{2}{*}{ Female } & Count & 21 & 23 & 6 & 50 \\
\hline & & $\%$ within Gender & $42.0 \%$ & $46.0 \%$ & $12.0 \%$ & $100.0 \%$ \\
\hline \multirow{3}{*}{ Total } & & Count & 39 & 45 & 16 & 100 \\
\hline & & $\%$ within Gender & $39.0 \%$ & $45.0 \%$ & $16.0 \%$ & $100.0 \%$ \\
\hline & & $\%$ within Anatomical Position & $100.0 \%$ & $100.0 \%$ & $100.0 \%$ & $100.0 \%$ \\
\hline
\end{tabular}

Table 4. Measurements made at lingual foramen and buccal end of the lingual canal

\begin{tabular}{|l|c|c|c|}
\hline Anatomical landmarks & Male & Female & P-value \\
\hline $\begin{array}{l}\text { LF - Alveolar crest } \\
\text { distance. }\end{array}$ & $12.14(4.53)$ & $11.24(2.67)$ & .508 \\
\hline $\begin{array}{l}\text { LF - inferior cortex } \\
\text { distance }\end{array}$ & $9.95(3.84)$ & $9.45(2.46)$ & .685 \\
\hline LF - Buccal plate distance. & $9.38(2.68)$ & $8.88(3.30)$ & .029 \\
\hline $\begin{array}{l}\text { Buccal end of LC - } \\
\text { Alveolar crest distance. }\end{array}$ & $13.45(5.39)$ & $12.95(2.40)$ & .175 \\
\hline $\begin{array}{l}\text { Buccal end of LC - inferior } \\
\text { cortex distance. }\end{array}$ & $8.20(2.49)$ & $7.70(3.08)$ & .059 \\
\hline $\begin{array}{l}\text { Buccal end of LC - Buccal } \\
\text { plate distance. }\end{array}$ & $6.50(2.44)$ & $6.00(2.45)$ & .006 \\
\hline
\end{tabular}

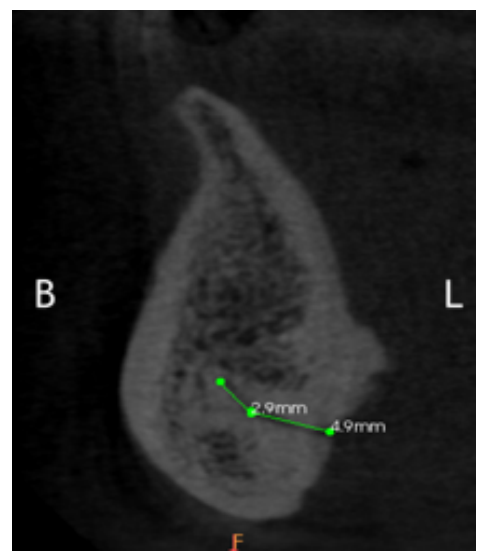

Figure 7. Length of the lingual canal

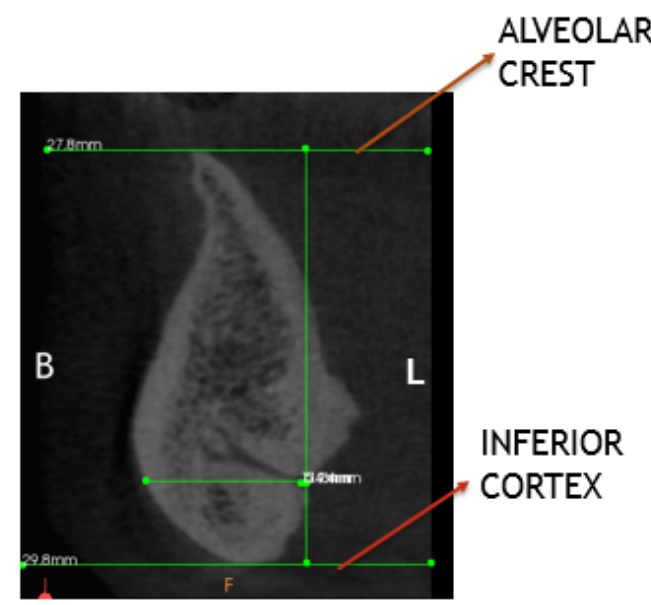

Figure 8. Lingual foramen(LF) measurements

LF - Alveolar crest distance.

LF - inferior cortex distance.

LF - Buccal plate distance. mouth when injured.The mean distances between the openings of the lingual canals at the labial side and alveolar crest, lower border of the mandible, and buccal plate were 12.64 (SD 4.53), 9.95 (SD 3.84), and 9.38 (SD 2.68) $\mathrm{mm}$, respectively.

The mean diameter of the opening of the lingual canals and at the buccal end of lingual canal(labial side), it was 0.86 (SD 0.37) $\mathrm{mm}$. The mean distances between the openings of the lingual canals at the labial side and alveolar crest, lower border of the mandible, and buccal plate were 13.45 (SD 5.39), 8.20 (SD 2.49), and 6.5 (SD 2.44) mm.

No significant differences were observed in the vertical angulation at lingual end between the genders $(P=0.67)$. The standard deviation of the average vertical angulation of the LFs was 21.11. No relationship was detected.

Significant differences were observed in the vertical angulation of lingual foramen measured in buccal end between genders $(\mathrm{P}=0.045)$. The standard deviation of the average vertical angulation of the LFs was 21.53. Also significant differences were observed in the horizontal angulation of lingual foramen measured in axial section between genders $(\mathrm{P}=0.032)$. The standard deviation of the average horizontal angulation of the LFs was 5.94. (Table 5)

\section{Discussion}

The presence of accessory foramina in mandible is frequently overlooked in clinical procedures [5]. It is important to note that these anatomical variations might only be preoperatively assessed radiologically and such observation might have influence on the therapeutic success. Small foramina are often observed on the anterior surface of the mandible and near the premolars of the lingual mandible. Tagaya et al., named these median lingual foramina and lateral lingual foramina, respectively [2].

The content of this foramen has been a matter of debate. Some studies assume a vascular content, its being an anastomosis of the sublingual branch of the right and left lingual arteries [6]. The artery could be of sufficient size to provoke a hemorrhage intraosseously or in the connective soft tissue, which might be difficult to control. Previous studies have been performed about frequency, diameter, and other anatomical features of lingual foramen and its canals. The purpose of the present study was to investigate the prevalence and anatomical variations of lingual foramen among South Indian population.

In our study, 100 mandibles were investigated and all of the images had at least one lingual foramen. Our results support those of Gahleitner et al.,Sheiki et al. [6], Tepper et al. [7] and Mc Donnell et al. [8] studies.

The location of lingual foramen and canal is important to avoid complications during surgery in that region. For instance, the mean distances between the lingual foramen and buccal end of LC to the 


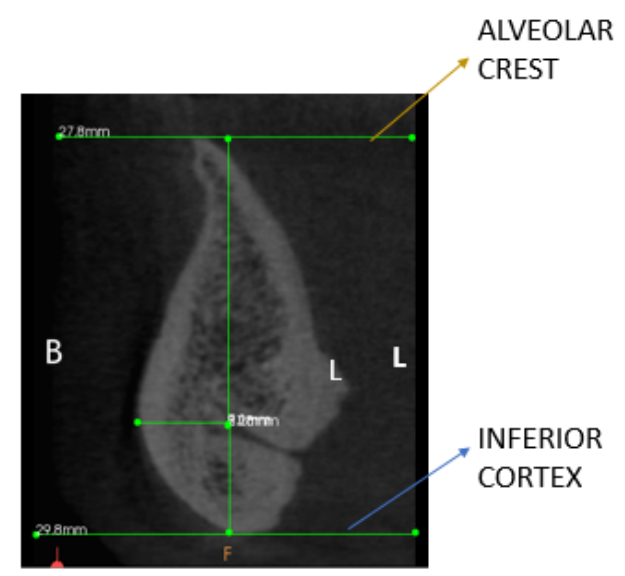

Figure 9. Measurements at buccal end of lingual canal

Buccal end of LC - Alveolar crest distance.

Buccal end of LC - inferior cortex distance.

Buccal end of LC - Buccal plate distance.

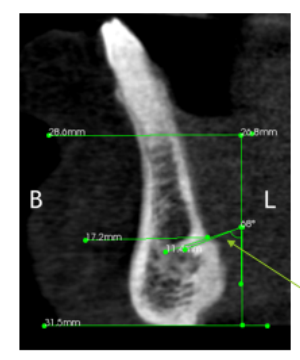

\begin{tabular}{|l|}
\hline THE VERTICAL \\
ANGULATION OF THE \\
LINGUAL CANAL AT \\
THE LINGUAL \\
FORAMEN \\
\hline
\end{tabular}

Figure 10. The vertical angulation of the lingual canal at the lingual foramen

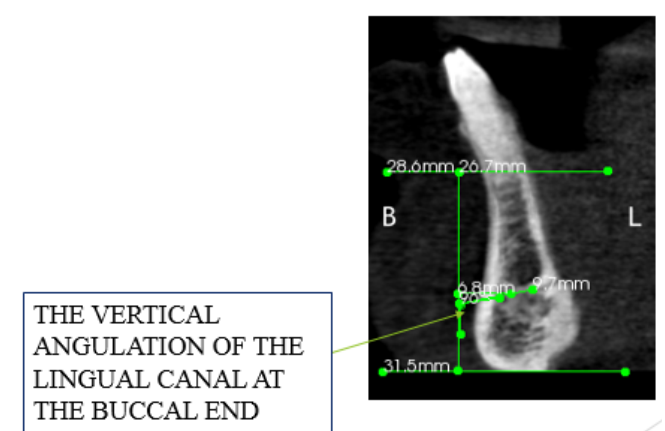

Figure 11. The vertical angulation of the lingual canal at the buccal end

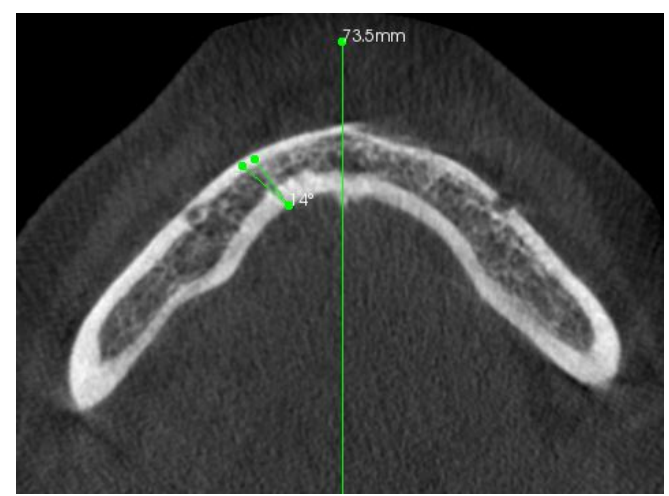

Figure 12. The horizontal angulation of the lingual canal

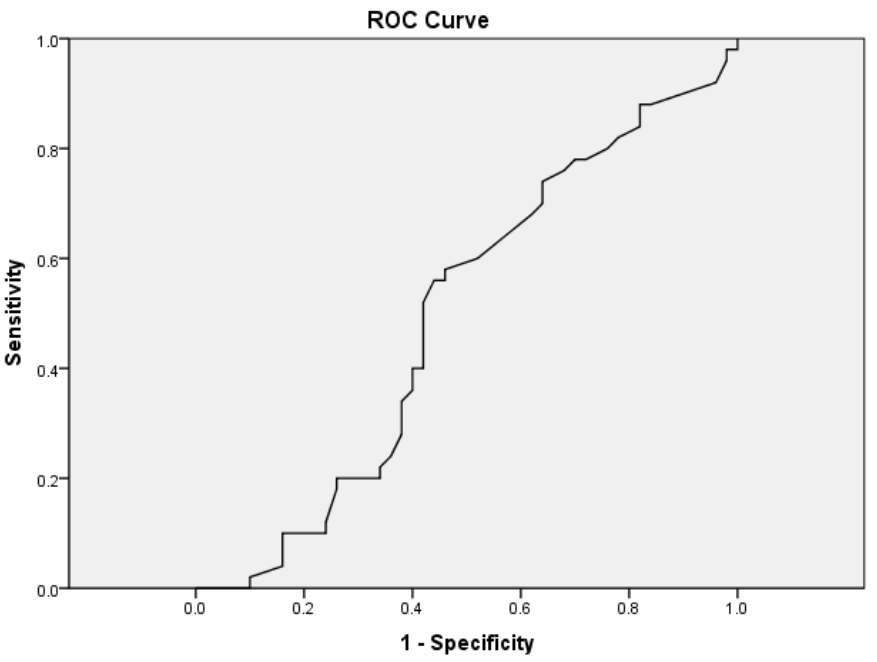

Figure 13. receiver operating characteristic curve (roc curve)

Table 5. Angulations at the lingual foramen and buccal end of the lingual canal

\begin{tabular}{|l|c|c|c|}
\hline \multicolumn{1}{|c|}{ GENDER } & MALE & FEMALE & P-value \\
\hline $\begin{array}{l}\text { The vertical angulation of the lingual } \\
\text { canal at the lingual foramen }\end{array}$ & $85.80(21.11)$ & $84.80(14.15)$ & 0.672 \\
\hline $\begin{array}{l}\text { The vertical angulation of the lingual } \\
\text { canal at the buccal end }\end{array}$ & $84.71(20.53)$ & $83.71(14.07)$ & 0.045 \\
\hline $\begin{array}{l}\text { The horizontal angulation of the } \\
\text { lingual canal }\end{array}$ & $18.72(5.94)$ & $17.12(4.87)$ & 0.032 \\
\hline
\end{tabular}

lower border of the mandible were 9.38 (SD 2.68) and 6.5 (SD 2.44) $\mathrm{mm}$, respectively. While Kawai et al. [9] on Japanese mandibles showed that distances from the inferior mandibular plane were 11.43 (SD 1.56) and 4.42 (SD 2.64) mm, respectively. As it can be obtained, the mean distance between the superior and inferior lingual foramina from lower border of the mandible was lesser in South Indian population rather than other populations in previous studies.

Also, the mean height of the opening of the superior and inferior lingual canals at the labial side from lower border of the mandible were 12.64 (SD 4.53) and 8.20 (SD 2.49) mm respectively, in order to their appearance, which is similar to Liang et al. [4], which reported that the mean height of the superior and inferior lingual canals from the lower cortical border were 11.5 (SD 2.8) and 7.4 (SD 2.4) mm, respectively.

In a previous study performed by Liang et al. [4], they showed that $72 \%$ of the canals had courses running downwards to the labial side and $28 \%$ of the canals were directed upward to the labial side. In the study we conducted, the majority of the superior lingual canals were running downward to the labial side.

And most of the inferior lingual canals were directed upward to the labial side, which is similar to Kawai et al. [10], study. These canal directions may explain the slightly vertical-oval morphology of midline lingual foramina.

The intraosseous canals connecting with the lingual foramina tended to run straight into the mandible about $3-5 \mathrm{~mm}$ from the surface of the lingual cortex, which is why we measured the entrance angulation of the canals in this study. The vertical angulation of lingual canal at lingual foramen, vertical angulation of lingual canal at the buccal end and the horizontal angulation of the canals were measured first only in our study.

Since the anatomical details of the lingual foramina are important to various fields of dentistry and oncology, the clinical interest is extensive 
and anatomical references about this in South Indian population are scarce, we aimed to submit this investigation to the medical and dental literature.

A limiting factor in the present study was the small sample size and we suggest that further studies to be performed on a larger group of subjects of different age and ethnicity. It is also suggested that lingual foramen should be compared in adults and children as well as in subjects with specific craniofacial diseases.

\section{Conclusion}

In this present study, we found some variations in mentioned anatomical landmarks in South Indian population in comparison with previous studies. Due to these findings, we suggest that according to different anatomical positions and measurement for lingual foramen and its bony canal in every individual, it is important to consider this point during preoperative planning for surgery and especially, for implant placement in the anterior mandible. Furthermore, CBCT imaging was able to show the anatomical features of the lingual foramen and its bony canal, to avoid post operative complications.

\section{References}

1. Del Castillo-Pardo de Vera JL, López-Arcas Calleja JM, Burgueño-García M (2008) Hematoma of the floor of the mouth and airway obstruction during mandibular dental implant placement: A case report. Oral Maxillofac Surg 12: 223-226. [Crossref]
2. Kim DH, Kim MY, Kim CH (2013) Distribution of the lingual foramina in mandibular cortical bone in Koreans. J Korean Assoc Oral Maxillofac Surg 39: 263-268. [Crossref]

3. Gintaras Juodzbalys, Hom-Lay Wang, Gintautas Sabalys (2010) Anatomy of Mandibular Vital Structures. Part I: Mandibular Canal and Inferior Alveolar Neurovascular Bundle in Relation with Dental Implantology. J Oral Maxillofac Res 1: 1. [Crossref]

4. Liang X, Jacobs R, Lambrichts I, Vandewalle G (2007) Lingual foramina on the mandibular midline revisited: a macroanatomical study. Clin Anat 20: 246-251. [Crossref]

5. Neves FS, Torres MG, Oliveira C, Campos PS, Crusoé-Rebello I (2010) Lingual accessory mental foramen: a report of an extremely rare anatomical variation. $J$ Oral Sci 52: 501-503. [Crossref]

6. Mahnaz Sheikhi, Mosavat F, Ahmadi A (2012) Assessing the anatomical variations of lingual foramen and its bony canals with CBCT taken from 102 patients in Isfahan. Dent Res J (Isfahan) 9. [Crossref]

7. Gahleitner A, Hofschneider U, Tepper G, Pretterklieber M, Schick S, et al. (2001) Lingual vascular canals of the mandible: evaluation with dental CT. Radiology 220 186-189. [Crossref]

8. McDonnell D, Reza Nouri M, Todd ME (1994) The mandibular lingual foramen A consistent arterial foramen in the middle of the mandible. J Anat 184: 363-369. [Crossref]

9. Taisuke K (2007) Classification of the lingual foramina and their bony canals in the median region of the mandible: cone beam computed tomography observations of dry Japanese mandibles. Oral Radiol 23: 42-48.

10. Kawai T, Asaumi R, Sato I, Yoshida S, Yosue T (2009) Classification of the lingual foramina and their bony canals in the median region of the mandible; cone beam computed tomography observation of dry human mandibles. Oral Radiol 23: 42-48.

Copyright: (2017 Kumar AG. This is an open-access article distributed under the terms of the Creative Commons Attribution License, which permits unrestricted use, distribution, and reproduction in any medium, provided the original author and source are credited. 